\title{
Liquidity indicator for the Croatian economy - Factor analysis approach ${ }^{\dagger}$
}

\author{
Mirjana Čižmešija ${ }^{1, *}$, Nataša Kurnoga ${ }^{1}$ and Vlasta Bahovec ${ }^{1}$ \\ ${ }^{1}$ Faculty of Economics and Business, University of Zagreb \\ J. F. Kennedy 6, 10000 Zagreb, Croatia \\ E-mail: 〈\{mcizmesija,nkurnoga, vbahovec\}@efzg.hr〉
}

\begin{abstract}
Croatian business surveys (BS) are conducted in the manufacturing industry, retail trade and construction sector. In all of these sectors, manager's assessments of liquidity are measured. The aim of the paper was to form a new composite liquidity indicator by including business survey liquidity measures from all three covered economic sectors in the Croatian economy mentioned above. In calculating the leading indicator, a factor analysis approach was used. However, this kind of indicator does not exist in a Croatia or in any other European economy. Furthermore, the issue of Croatian companies' illiquidity is highly neglected in the literature.

The empirical analysis consists of two parts. In the first part the new liquidity indicator was formed using factor analysis. One factor (representing the new liquidity indicator; LI) was extracted out of the three liquidity variables in three economic sectors. This factor represents the new liquidity indicator. In the second part, econometric models were applied in order to investigate the forecasting properties of the new business survey liquidity indicator, when predicting the direction of changes in Croatian industrial production. The quarterly data used in the research covered the period from January 2000 to April 2013. Based on econometric analysis, it can be concluded that the LI is a leading indicator of Croatia's industrial production with better forecasting properties then the standard liquidity indicators (formed in a manufacturing industry).
\end{abstract}

Key words: Leading indicator, Liquidity measure, Factor analysis

Received: September 23, 2014; accepted: December 10, 2014; available online: December 30, 2014

\section{Introduction}

The Croatian system of business cycle research mostly relies on the Business and Consumer Surveys (BCS). BCS represents qualitative assessments of

\footnotetext{
${ }^{\dagger}$ This work has been fully supported by Croatian Science Foundation under the project 3858 "The role of economic sentiment in explaining macroeconomic trends: methodological improvements and new areas of application"

${ }^{*}$ Corresponding author. 
managers' and consumers' judgments about the past, present and future tendencies of the key variables from their economic surroundings. Since 1961, the BCS have been fully synchronized on the EU level through The Joint Harmonized EU Programme of Business and Consumer Surveys. This document regulates and unifies the methodology of conducting BCS, which enables direct comparability of their results between various EU Member States [5]. The surveys are carried out on a regular monthly basis in different economic sectors of each country: the industrial sector, retail trade, construction, services and the consumer sector.

The recent global financial crisis has opened a variety of economic fields which could fairly benefit from Business Survey (BS) results. Namely, the BS offer direct empirical assessment of the otherwise "intangible" factors such as economic agents' perceptions and expectations [10].

The main idea is to apply micro (survey) data in modeling macroeconomic aggregates [2]. Using business survey results, many indicators with different forecasting properties are (and can be) calculated. They are based on different methodological ground and can be used as a coincident or lagging indicator, not only as a leading indicator $[7,9]$.

"It has to be kept in mind that there is no general construction principle for a perfect composite leading indicator" [6]. Therefore, the aim of this paper was to continue the research process started in 2012 in developing a new business survey liquidity indicator for the Croatian economy with the integration of BS results in retail trade and construction (in addition to the manufacturing industry) into the new composite leading indicator. In the paper by [4] a simple business survey liquidity measure (calculated only in the manufacturing industry) was defined as the (seasonally adjusted) balance between the weighted percentages of the positive $(+)$ and negative $(-)$ managers' responses to the question: "Liquidity of your firm is: (+) good, (=) with temporary problems, (-) bad". The result of that study showed that the changes in the liquidity measure can predict the direction of changes in industrial production with one or two quarters lead. In that way forecasting properties of this indicator were confirmed. It can also serve as a proxy for the widely used Industrial confidence indicator (ICI). In this (new) research, a factor analysis approach was used in calculating the new composite liquidity leading indicator (LI). Time series analysis applied in the paper confirmed its forecasting properties. Since the new indicator includes components from the manufacturing industry, construction and retail trade, it can be used to forecast changes in the whole national economy, not only in the industrial sector. 


\section{Business survey liquidity measure in Croatian business surveys}

Croatian business surveys started in 1995. They are conducted in accordance with the harmonized European methodology $y^{\ddagger}$ However, the Croatian questionnaire offers some added value in comparison to the harmonized EU questionnaire applied in all EU Member States, such as the question regarding managers' perception of the company's liquidity level. Namely, this question was introduced in the Privredni vjesnik survey at the sole beginning of conducting the surveys in Croatia because at that time illiquidity was one of the most pronounced problems of the Croatian economy. With time the problem was considerably reduced, but the recent economic hardship again put the focus of economic researchers and practitioners on this issue. The stated question is present in the questionnaire for the manufacturing industry, retail trade and the construction sector, and since 2008 in the service sector as well.

Managers' liquidity assessments expressed as answers to the business survey question: "Liquidity of your firm is: $(+)$ good, (=) with temporary problems, (-) bad" are translated into quantitatively expressed indicators. First of all, balances of responses have to be calculated. Balance is the difference between weighted percentages of positive and negative answers to the corresponding question. Seasonally adjusted balances ${ }^{\S}$ of managers' liquidity assessments can be used as the business survey liquidity measure (liquidity indicator) [4]. Figure 1 depicts the business survey liquidity measures (time series of seasonally adjusted balances) in the manufacturing industry, construction and retail trade sectors.

Figure 1 shows that liquidity variables in construction (LI_C) and in retail trade (LI_RT) have a similar pattern in the whole period of analysis. The pattern of the liquidity variable in manufacturing industry (LI_MI) was the same as the pattern of all other variables only in the period before 2008 (before recession). It is a reason to calculate a new liquidity indicator to compose managers' assessments in three dominant economic sectors (not only in the manufacturing industry) with the aim to calculate a composite leading indicator which can be a proxy for the Economic Sentiment Indicator (ESI).

¥The essence of the Croatian and the EU Business surveys is explained in [3].

$\S$ The European Commission and Croatia use the DAINTIES seasonal adjustment method. 


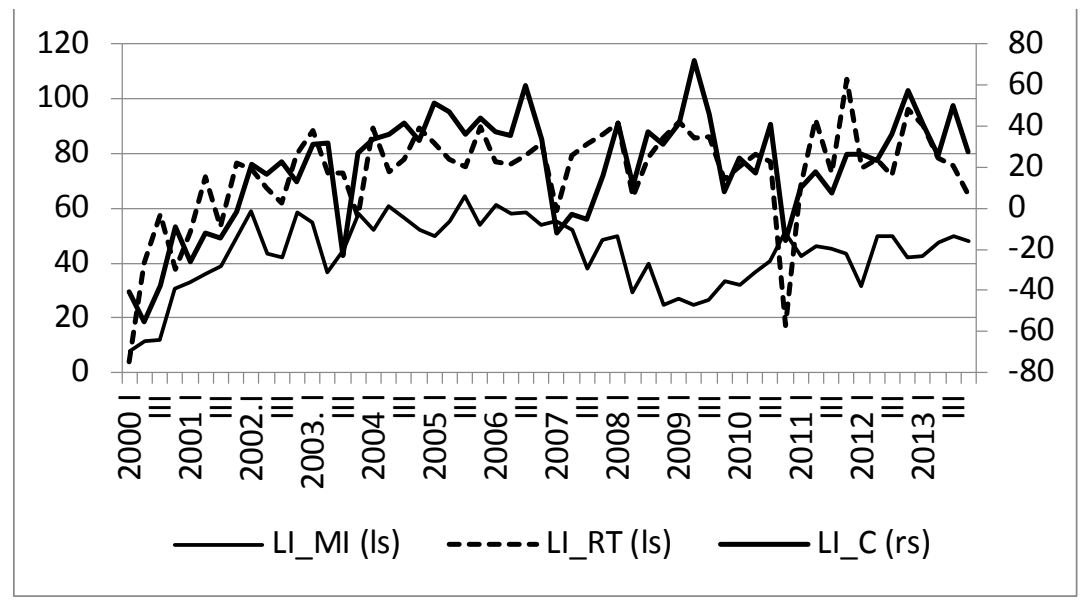

Notes: (rs) - right scale, (ls) - left scale

Figure 1: Business survey liquidity measures in three Croatian economic sectors

\section{Data set and methodology}

The data set for the first part of the analysis contains quarterly time series of three business survey liquidity measures (from the manufacturing industry, construction and retail trade). Time series are seasonally adjusted using the DAINTIES method. The Augmented Dickey-Fuller (ADF) unit root tests for business survey liquidity measures (liquidity variables) were conducted. All variables satisfied the stationarity condition (on the conventional significance level of 5\%). Then, the new confidence liquidity indicator was calculated using factor analysis. In the second part of the analysis, their forecasting power was analysed using VAR methodology. In addition, quarterly time series of the Economic Sentiment Indicator and industrial production (expressed as the percentage rate of change) was used to compare with the liquidity indicators. The Granger-causality test was carried out to determine whether the new liquidity indicator, ESI and the standard liquidity indicator have explanatory power for future values in the reference series of industrial production or vice versa. Like in similar empirical research, the limitation of the study is that in Granger tests, the significance level of $10 \%$ (not $5 \%$ or $1 \%$ ) was used. The covered period of analysis was from 2000Q1 to 2013Q4. The data sources were Privredni vjesnik and the Croatian Bureau of Statistics.

Abbreviations used in the study are as follows: LI_C - a liquidity variable in construction, LI_RT - a liquidity variable in retail trade, LI_MI - a liquidity variable in the manufacturing industry, LI - a new liquidity indicator (factor analysis approach), IP_R - the rate of change of industrial production 
$(\varnothing 2000=100)$, LI_0 - the standard liquidity indicator, ESI - the Economic Sentiment Indicator, ESI_R - the percentage rate of change in economic sentiment, LI(-1), LI(-2), LI(-3), LI(-4), LI(-5) - a new liquidity indicator with different lags (1 to 5 quarters), LI_0(-1), LI_0(-2), LI_0(-3), LI_0(-4), LI_0($5)$ - the standard liquidity indicator with different lags (1 to 5 quarters).

\section{Empirical results}

The principal component factor analysis was used to form the new liquidity indicator for the Croatian economy. It was performed on three liquidity variables: LI_MI, LI_C and LI_RT. Factor analysis has been conducted in the following steps: examination of the assumptions in factor analysis (stationarity, examination of the correlations and measure of sampling adequacy - MSA), extraction of factors and calculation of factor scores.

\begin{tabular}{|c|ccc|}
\hline Variables & LI_MI & LI_C & LI_RT \\
\hline LI_MI & 1.00000 & 0.44688 & 0.35875 \\
& & $(0.0006)$ & $(0.0066)$ \\
\hline LI_C & 0.44688 & 1.00000 & 0.68398 \\
& $(0.0006)$ & & $(<.0001)$ \\
\hline LI_RT & 0.35875 & 0.68398 & 1.00000 \\
& $(0.0066)$ & $(<.0001)$ & \\
\hline
\end{tabular}

Table 1: Pearson correlation coefficients $r$, p-values (in brackets)

The Augmented Dickey-Fuller (ADF) unit root tests were performed and the processes are considered to be stationary. Inspection of the correlation matrix given in Table 1 reveals that all coefficients are higher than 0.3 and are significant at the $1 \%$ significance level. The values of Kaiser's measure of sampling adequacy (MSA) are given in Table 2 and it can be seen that all values (the MSA values for each variable and overall MSA) are greater than 0.5. According to all mentioned conditions, the data are suitable for the application of factor analysis. 


\begin{tabular}{|l|c|}
\hline Variables & MSA values \\
\hline LI_MI & 0.77712396 \\
\hline LI_C & 0.58128967 \\
\hline LI_RT & 0.59867740 \\
\hline Overall MSA & 0.62027210 \\
\hline
\end{tabular}

Table 2: Kaiser's Measure of Sampling Adequacy

Table 3 give the eigenvalues and proportions. According to the Kaiser criterion (all factors that have eigenvalues greater than one should be extracted), only one factor was extracted. This extracted factor alone explains $66.9 \%$ of the total variance of three analysed variables.

\begin{tabular}{|c|c|c|c|}
\hline Factors & Eigenvalues & $\begin{array}{c}\text { Proportions } \\
\text { of variance explained }\end{array}$ & $\begin{array}{c}\text { Cumulative proportions } \\
\text { of variance explained }\end{array}$ \\
\hline 1 & 2.00698248 & 0.6690 & 0.6690 \\
\hline 2 & 0.68549999 & 0.2285 & 0.8975 \\
\hline 3 & 0.30751753 & 0.1025 & 1.0000 \\
\hline
\end{tabular}

Table 3: Eigenvalues, proportions and cumulative proportions of variance explained

In practice, factor loadings between \pm 0.3 and \pm 0.4 are considered to meet the minimal level for the interpretation of structure, loadings \pm 0.5 or greater are considered practically significant, whereas loadings exceeding \pm 0.7 are considered indicative of a well-defined structure [8]. Factor loadings are given in Table 4. It is obvious that they are all higher than 0.6 and that they are satisfactory. The final communality estimates are also given in Table 4 and it can be seen that all communalities are sufficiently high.

\begin{tabular}{|l|c|c|}
\hline Variables & Factor1 & Final communality estimates \\
\hline LI_MI & 0.69864 & 0.48810104 \\
\hline LI_C & 0.88947 & 0.79116451 \\
\hline LI_RT & 0.85306 & 0.72771693 \\
\hline
\end{tabular}

Table 4: Factor loadings and final communality estimates

For the purpose of further analysis factor scores were calculated for one retained factor - the new liquidity indicator. In principal component factor analysis factor scores are actual scores and they were calculated based on the matrix of standardized scoring coefficients given in Table 5. The calculated factor scores were used in subsequent analysis. 


\begin{tabular}{|l|l|}
\hline Variables & Factor1 \\
\hline LI_MI & 0.34811 \\
\hline LI_C & 0.44319 \\
\hline LI_RT & 0.42505 \\
\hline
\end{tabular}

Table 5: Standardized Scoring Coefficients

The reference series in research is industrial production as a representative of the Croatian national economy. Namely, industrial production accounts for almost $25 \%$ of the Croatian GDP and $60 \%$ of industrial production are generated in the manufacturing industry. Moreover, it has been shown in several Croatian empirical studies that the Croatian GDP follows the movement of Croatian industrial production.

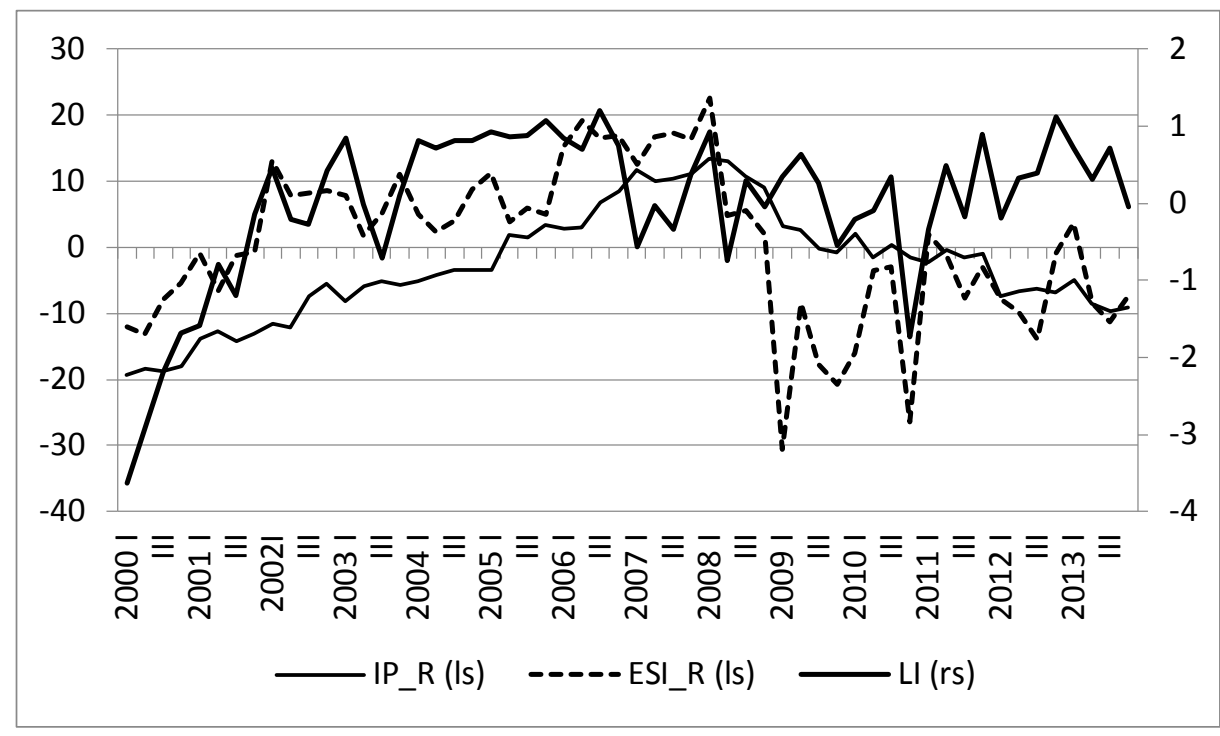

Notes: (rs) - right scale, (ls) - left scale

Figure 2: Industrial production and business survey composite indicators

In Figure 2, it can be seen that industrial production, ESI and the new liquidity indicator share a similar pattern. In accordance with the harmonized EU methodology, it is of interest to track only the direction of changes in the reference series, not the amount of changes. The main reason for that is the fact that the business survey research is not aimed at expressing a quantification of changes, but only the direction of changes in the national economy. 
The second part of analysis was continued by applying VAR methodology [1]. The aim of the analysis is not to quantify the relationship between the variables in the model, but to examine the possibility of using leading indicators (LI, ESI and LI_0) in predicting changes of industrial production.

First of all, the ADF tests were performed for all time series in the model. The appropriate lag length in the ADF specification has been determined using the Akaike Information Criterion with the maximum number of lags set to 10 (shown in brackets). The ADF t-statistics and $p$-values are presented in Table 6.

In accordance with results presented in Table 6 , it can be seen that variables in the model are stationary (at the usually used significance level). The next step of analysis was the optimal lag number determination.

\begin{tabular}{|l|c|c|}
\hline Variable & ADF value & $p$-value \\
\hline LI & $-4.514416(0)$ & 0.0000 \\
\hline IP_R & $-1.976760(0)$ & 0.0468 \\
\hline LI_0 & $-3.541683(0)$ & 0.0104 \\
\hline ESI_R & $-2.063207(7)$ & 0.0387 \\
\hline
\end{tabular}

Table 6: ADF Unit root test results for the observed series in level

Using the Akaike information criterion, the lag length was set to five quarters. The 5 quarters lag length was confirmed by the results presented as follows. The Granger-causality test was used to determine whether the LI, ESI and LI_0, as leading indicators, have explanatory power for future values in the reference series of industrial production or vice versa (Table 7).

\begin{tabular}{|c|c|c|}
\hline & $F$-Statistic & $p$ - value \\
\hline Null Hypothesis (lag 1) & 0.34920 & 0.5571 \\
\hline LI does not Granger Cause IP_R & 0.34574 & 0.5591 \\
\hline IP_R does not Granger Cause LI & 0.32883 & 0.7213 \\
\hline Null Hypothesis (lag 2) & 0.5929 \\
\hline LI does not Granger Cause IP_R & 0.52834 & 0.9149 \\
\hline IP_R does not Granger Cause LI & 0.17188 & 0.4820 \\
\hline Null Hypothesis (lag 3) & 0.83430 \\
\hline LI does not Granger Cause IP_R & 0.8907 \\
\hline IP_R does not Granger Cause LI & 0.4680 \\
\hline Null Hypothesis (lag 4) & 0.90779 \\
\hline LI does not Granger Cause IP_R & $0.0757^{*}$ \\
\hline IP_R does not Granger Cause LI & 0.4090 \\
\hline Null Hypothesis (lag 5)
\end{tabular}

Notes: *at the $10 \%$ significance level

Table 7: Granger causality test results (different lags) for $I P \cdot R$ and $L I$ 
It can be seen that the new liquidity indicator (LI) Granger causes industrial production (only for five quarter lags) at the $10 \%$ significance level, but industrial production does not Granger cause the liquidity indicator. This means that shifts in LI proceed to those of industrial production. Granger causality was examined for other leading indicators in the model. The results are presented in Table 8 .

\begin{tabular}{|c|c|c|}
\hline & F-Statistic & $p$ - value \\
\hline \multicolumn{3}{|l|}{ Null Hypothesis (lag 5) } \\
\hline LI_0 does not Granger Cause IP_R & 1.77933 & 0.1392 \\
\hline IP_R does not Granger Cause LI_0 & 2.20640 & $0.0726^{*}$ \\
\hline \multicolumn{3}{|l|}{ Null Hypothesis (lag 5) } \\
\hline ESI_R does not Granger Cause IP_R & 4.41461 & $0.0027^{*}$ \\
\hline $\mathrm{IP} \_\mathrm{R}$ does not Granger Cause ESI_R & 1.97184 & 0.1039 \\
\hline
\end{tabular}

Notes: *at $10 \%$ significance level

Table 8: Granger causality test results (5 lags)

Composite indicator ESI confirms their forecasting properties. ESI Granger causes industrial production (with five quarters lag), but the standard liquidity indicator (LI_0) does not Granger cause industrial production.
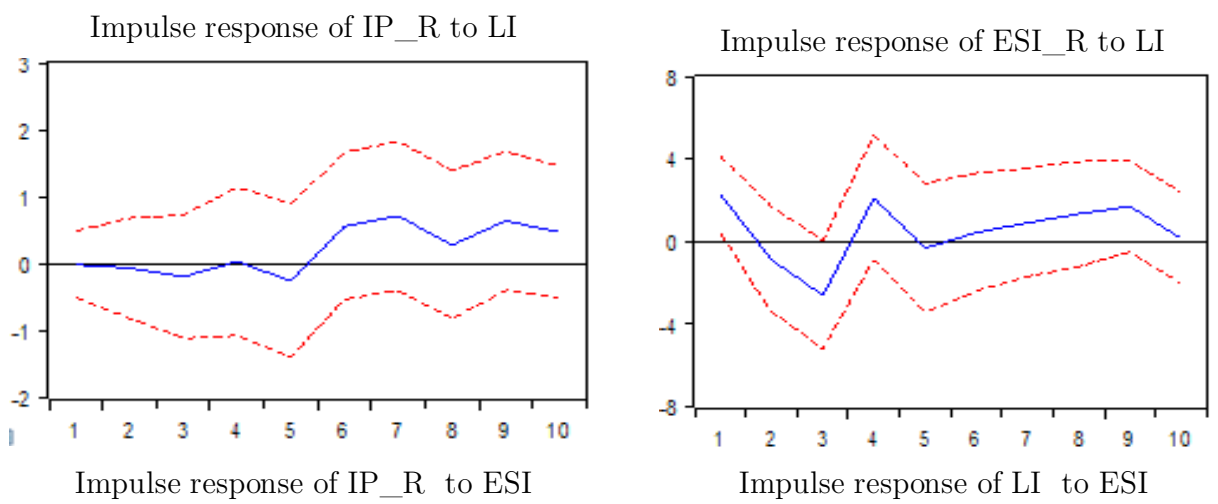

Impulse response of IP_R to ESI

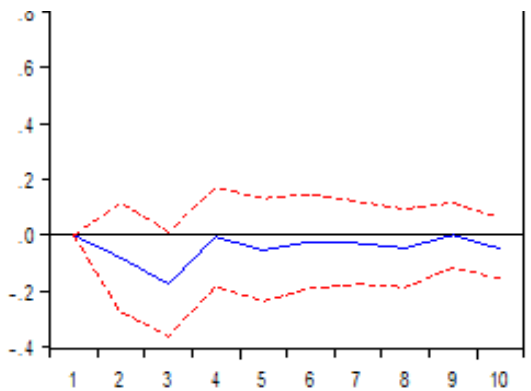

Figure 3: Impulse response functions 
The dynamics of the relationships between confidence indicators and industrial production were examined employing the impulse response functions (Figure 3). Solid line represents the impulse response function, while the $+/-2$ standard error limits are represented by dotted lines. The influence of a shock in LI is the highest in the sixth future quarter.

Results of forecasting error variance decomposition presented in Table 9 confirm the same conclusion. The variable IP_R itself explains $100 \%$ of its forecasting error variance in the first future period. $3.7 \%$ of the error in the forecast of IP_R is attributed to LI after two years.

\begin{tabular}{|c|c|c|c|c|}
\hline Period & LI & IP_R & ESI_R & LI_0 \\
\hline 1 & 0.000000 & 100.0000 & 0.000000 & 0.000000 \\
\hline 2 & 0.054014 & 92.12699 & 7.018402 & 0.800591 \\
\hline 3 & 0.372176 & 73.71331 & 16.50595 & 9.408562 \\
\hline 4 & 0.254946 & 61.48301 & 22.43988 & 15.82217 \\
\hline 5 & 0.525026 & 55.85144 & 22.81919 & 20.80435 \\
\hline 6 & 1.922837 & 54.97357 & 23.87273 & 19.23086 \\
\hline 7 & 3.718264 & 52.94136 & 25.44578 & 17.89459 \\
\hline 8 & 3.709804 & 53.44634 & 25.08337 & 17.76049 \\
\hline
\end{tabular}

Table 9: Variance decomposition of $I P^{\cdot} R$

The highest (and statistically significant) correlation coefficient between industrial production (IP_R) and the composite liquidity indicator (LI) was obtained for the lag of 5 quarters (Table 10). It means that changes in the liquidity indicator can predict changes in industrial production for 5 quarters ahead.

\begin{tabular}{|l|l|l|l|l|l|l|l|}
\hline Variable & LI & LI(-1) & LI(-2) & LI(-3) & LI(-4) & LI(-5) & ESI_R \\
\hline $\begin{array}{l}\text { Correlation } \\
\text { coefficient }\end{array}$ & 0.11934 & 0.20606 & $0.31779 *$ & $0.41713^{*}$ & $0.47571^{*}$ & $\mathbf{0 . 6 1 8 7 9 *}$ & $0.33066^{*}$ \\
\hline p-value & 0.40420 & 0.14690 & 0.02310 & 0.00230 & 0.00040 & $\mathbf{0 . 0 0 0 0 0}$ & 0.01780 \\
\hline
\end{tabular}

Notes: *at $5 \%$ significance level

Table 10: Correlation coefficient between IP-R and LI (different lags) and ESI

For the standard liquidity indicator (LI_0) the results of correlation analysis are similar, but the correlation coefficient (for the 5 quarters lag) is smaller than the same correlation coefficient between IP_R and LI (Table 11). 


\begin{tabular}{|c|c|c|c|c|c|c|}
\hline Variable & LI_0 & LI_0(-1) & LI_0(-2) & LI_0(-3) & LI_0(-4) & LI_0(-5) \\
\hline $\begin{array}{c}\text { Correlation } \\
\text { coefficient }\end{array}$ & -0.08162 & 0.06026 & 0.21702 & $0.37616^{*}$ & $0.46799^{*}$ & $\mathbf{0 . 5 4 4 6 8 *}$ \\
\hline p-value & 0.56910 & 0.67450 & 0.12610 & 0.00650 & 0.00050 & $\mathbf{0 . 0 0 0 0 0}$ \\
\hline
\end{tabular}

Table 11: Correlation coefficients between IP-R and LI'O (different lags)

Correlation analyses confirmed all survey results listed above.

\section{Conclusion}

The aim of this paper was to continue the research process started in 2012 in developing a new business survey liquidity indicator for the Croatian economy. A simple business survey liquidity measure (calculated only) in manufacturing industry was defined as the (seasonally adjusted) balance between the weighted percentages of the positive and negative managers' responses to the question about liquidity. Forecasting properties of this indicator were confirmed. The changes in the liquidity measure can predict the direction of changes in industrial production with one or two quarters lead. In this paper, some modifications and methodological improvements were carried out with the aim to construct the new leading indicator for the Croatian economy as a whole, with better forecasting properties (including two additional economic sectors in the analysis).

A composite liquidity indicator for the Croatian economy was formed applying multivariate statistical techniques (factor analysis). After that, its significance for explaining the reference macroeconomic series (industrial production) was tested using time series analysis and its predictive properties were analysed with regards to Croatian industrial production. On the basis of VAR models, it was concluded that the composite liquidity indicator (LI) can be used in forecasting changes of Croatian industrial production and the whole national economy with five quarters lag. Finally, the correlation analysis confirmed all previously mentioned results.

Additionally, the goal of this paper was to provide a unique contribution by postulating that companies' business decisions do not depend mainly on "hard data" such as the widely used liquidity measures (current ratio, quick ratio, financial stability ratio, etc.). On the contrary, this research explored the way managers' subjective perceptions of the companies' liquidity levels feed into their decisions and influence their investment decisions or the overall economic activity. 


\section{References}

[1] Asteriou, D. (2006). Applied Econometrics: A Modern Approach using EViews and Microfit, London: Pelgrave.

[2] Bierbaumer-Polly, J. (2010). Composite leading indicator for the Austrian economy: Methodology and "real-time" performance, WIFO Working Papers, 369.

[3] Čižmešija, M. (2008). Konjunkturni testovi Europske unije i Hrvatske (Business survay in European Union and in Croatia), Zagreb: Privredni vjesnik.

[4] Čižmešija, M. and Kurnoga Živadinović, N. (2012). Business survey liquidity measure as a leading indicator of Croatian industrial production, Croatian Operational Research Review (CRORR), 3, 280-288

[5] European Commission, the Directorate-General for Economic and Financial Affairs (2014). The Joint Harmonised EU Programme of Business and Consumer Surveys: User Guide, Brussels.

[6] Goldrian, G., Lindbauer, J.D. and Nerb, G. (2001). Evaluation and Development of Confidence Indicators Based on Harmonised Business and Consumer Surveys, European Commission: European economy.

[7] Graff, M. and Etter, R. (2004). Coincident and leading indicators of manufacturing industry. Sales, Production, Orders and Inventories in Switzerland, OECD Journal: Journal of Business Cycle Measurement and Analysis, 1/1, 109-131.

[8] Hair, J. F., Black, W.C., Babin, B. J. and Anderson, R. E. (2010), Multivariate Data Analysis, 7th Ed. Pearson, Upper Saddle River.

[9] Sillverstovs, B. (2013). Do business tendency surveys help in forecasting employment?: A real-time evidence for Switzerland, OECD Journal: Journal of Business Cycle Measurement and Analysis 10/2, 129-151.

[10] Sorić, P. (2013). Assessing the sensitivity of consumption expenditure to inflation sentiment in post-communist economies, Post-Communist Economies, 15/4, 529538. 